\title{
New Method for Assessing the Energy Potential of Wind Sites- A Case Study in Jordan
}

\author{
Ayman Al-Quraan*, Hussein Al-Masri, Ashraf Radaideh \\ Electrical Power Engineering Department, Yarmouk University, Irbid, Jordan
}

Received March 3, 2020; Revised May 1, 2020; Accepted May 13, 2020

Copyright $(\mathrm{O} 2020$ by authors, all rights reserved. Authors agree that this article remains permanently open access under the terms of the Creative Commons Attribution License 4.0 International License

\begin{abstract}
This paper presents a technical assessment of wind power potential for five promising wind sites in Jordan: Tafila, Zabda, Royal Scientific Society, Al-Alia and Al-Reesha wind sites. This assessment is based on developing a new methodology of estimating the wind energy by estimating the main wind parameters for a specific wind site. The developed methodology is originally based on a website data provided by the national wind energy atlas. Microsoft excel environment is used to estimate the total wind energy, the maximum repetition wind speed and the wind speed contributing the maximum energy in a specific wind regime. The validation process for this methodology has been carried out using measured wind speed data provided by the Energy Research Centre. The error between the estimated wind energy and the measured value is less than $10 \%$ for all cases. The highest energy is available in Tafilah wind site with around $6 \mathrm{MWh}$. In order to obtain an accurate comparison for the selected sites, the wind energy was estimated at uniform height, selected to be the standard height $(10 \mathrm{~m})$. The importance of this model is that it can be utilized routinely to assess the wind energy potential in a specific location, so a decision can be made whether a wind farm can be built or not in that location without any need to install anemometers.
\end{abstract}

Keywords Wind Energy, Energy Capture, Energy Conversion, Wind Farms, Wind Energy Integration

\section{Introduction}

Several methods are used for assessing wind resources in a specific wind site based on data measured by airports or meteorological stations. Basically, they can be grouped into several main categories [1-4]. The most dependable method for the wind assessment is to directly measure the wind speed, ideally at the position and the height of the proposed wind turbine. However, measuring the wind speed at a site is both time consuming and expensive, i.e. normally not appropriate for the early stages of wind energy development.

Fortunately, several methods are available for the initial assessment of wind resources, with varying degrees of resolution and accuracy. These are, in order of increasing accuracy, wind atlases, analytical method using several distribution functions, numerical methods including Computational Fluid Dynamics software (CFD) and wind tunnel modeling [5-8]. It was demonstrated by several research works that Weibull and Rayleigh distribution functions are very effective in modeling the wind resources analytically, especially in open areas where few obstacles exist [9-13].

Boudia et al. [9] have presented Algerian wind resource assessment using statistical analysis based on the measured wind speed data in the last decade from 63 meteorological stations distributed over the Algerian territory and 24 in neighboring countries close boundaries. The study, which used Weibull distribution to predict the seasonal wind power potential, gives spring as the windiest period over the largest part of the country. Paraschiv et al. in [10] have analyzed the wind power density in two sites in Constanta county, Romania, using Rayleigh probability density function. The mean wind speed data in hourly basis for the year of 2017 was used in this analysis. The reported power densities varied from 295.39 to $194.5 \mathrm{w} / \mathrm{m}^{2}$. Shoaib et al. in [11] have estimated the parameters of the Weibull probability distribution function, for 3-years wind speed data, averaged in a 10-minutes basis, from the Energy Development Board of Pakistan. Different numerical methods have been used in this estimation: Maximum Likelihood, Modified Maximum Likelihood, and Energy 
Pattern Factor Methods. The suitability of the fit was assessed using goodness-of-fit tests, such as Root Mean Square Error, Coefficient of Determination $\left(\mathrm{R}^{2}\right)$, and Chi-Square $\left(\chi^{2}\right)$ tests.

Azad et al. in [12] have analyzed the wind speed data, provided in a half-hourly basis, for three different wind sites in Australia using Weibull distribution function. Different methods are used to estimate the Weibull parameters of the available wind data: Method of Moments (MOM), Empirical Method (EM), and Power Density Method (PDM). It was observed that the accuracy of the EM method is the best among the three studied methods for calculating Weibull parameters. In [13], Bidaoui et al. evaluate and discuss the energy wind potential of five major cities in Northern Morocco. The theoretical analysis is based on stochastic models of Weibull and Rayleigh probability density functions. Various statistical accuracy indicators such as the $\mathrm{R}^{2}$ method, $\chi^{2}$ - error, RMSE and mean bias error (MBE) are considered.

This paper takes several wind sites in Jordan as research objects to review and compare main wind parameters: most frequent wind speed $\left(v_{\text {fmax }}\right)$, wind speed contributing maximum energy $\left(v_{E \max }\right)$ and energy density of the wind site $\left(E_{d}\right)$ which is derived in the paper, based on Weibull and Rayleigh distribution functions. Then evaluates the wind energy potential $\left(\mathrm{E}_{\mathrm{T}}\right)$ for the selected wind sites. The main objectives of the study with respect to those offered by other studies in the same area of research can be summarized as follows:

1. This paper provides a complete derivation of the main wind parameters for a technical assessment of a specific wind site. The model has been derived in terms of statistical distribution functions such as Weibull and Rayleigh, used in this paper.

2. Using real examples, this paper provides a technical assessment of wind power potential for different wind sites. The assessment of these wind sites was based on developing a new methodology of estimating the wind energy which can be utilized routinely. Therefore, a decision can be made whether a wind farm can be built or not without any need to install real anemometers.

3. The validation process was done using measured wind speed data provided by the National Energy Research Centre.

\section{Wind Modeling}

\subsection{Power-Speed Characteristics of the Wind}

The power available in a wind stream per unit area is expressed as follows [14-17]:

$$
P_{w}(v)=\frac{1}{2} \rho v^{3}
$$

Where $P_{w}$ is wind power in $\left(\mathrm{w} / \mathrm{m}^{2}\right), \rho$ is the air density $\left(1.224 \mathrm{~kg} / \mathrm{m}^{3}\right)$ and $v$ is the wind Speed in $(\mathrm{m} / \mathrm{s})$.

Since the power generated from the wind is a cubic function of wind speed, see (1), so a small difference in the prediction of the wind speed leads to a large variation in the estimation of the generated wind energy $[7,9]$. Therefore, an accurate method of estimation has to be developed to minimize the error in the prediction of wind energy.

\subsection{Wind Distribution}

Several density functions are used to describe the behavior of wind speed and its distribution [10-16]. The most common distribution functions used in the literature are Weibull and Rayleigh distribution functions in which Rayleigh function is a subset of the Weibull function. Weibull function has two distribution parameters while Rayleigh function has only one parameter [10,11]. Details about both distribution functions are described in this section.

The probability distribution function for any wind regime can be evaluated by finding the first derivative of the corresponding cumulative distribution function which gives the probability for all wind speeds less or equal to a specific wind speed $(v)$ in the wind regime [12-13],[16].

In the case of Weibull distribution, the corresponding cumulative distribution function $\left(F_{w}(v)\right)$ is given by [16]:

$$
F_{w}(v)=1-\exp \left[-\left(\frac{v}{c}\right)^{k}\right]
$$

Where $\mathrm{k}$ and $\mathrm{c}$ are shape and scale factors of Weibull curve.

Therefore, the probability for a specific wind speed based on Weibull distribution function $f_{w}(v)$, is given by:

$$
f_{w}(v)=\frac{d F_{w}(v)}{d v}=\left(\frac{k}{c}\right)\left(\frac{v}{c}\right)^{k-1} \exp \left[-\left(\frac{v}{c}\right)^{k}\right]
$$

Fig. 1 shows Weibull distribution function at different shape factors. The maximum repetition wind speeds $\left(v_{w f m a x}\right)$ is shown at the peak of each Weibull distribution function. It is clear that by increasing the shape factor of the wind regime, the peak of the Weibull distribution function is increased accordingly. The average wind speed $(\bar{v})$ based on this approach is given by [16-17]:

$$
\bar{v}=\int_{0}^{\infty} v f_{w}(v) d v=\int_{0}^{\infty} v\left(\frac{k}{c}\right)\left(\frac{v}{c}\right)^{k-1} \exp \left[-\left(\frac{v}{c}\right)^{k}\right] d v
$$

Equation 4 can be simplified using a Gamma function as follows:

$$
\bar{v}=c \Gamma\left(1+\frac{1}{k}\right)
$$




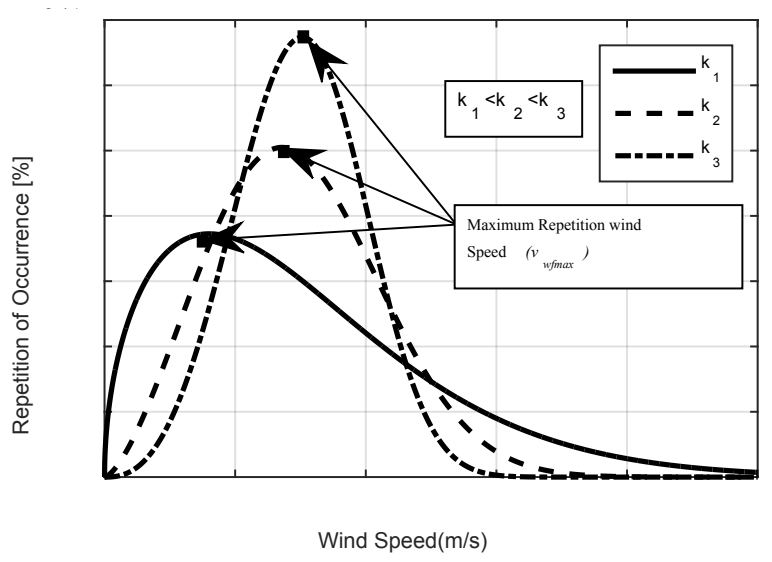

Figure 1. Weibull distribution function at different shape factors

Rayleigh distribution function is a special case of Weibull distribution function [23], where the shape factor, $\mathrm{k}=2$. By substituting $\mathrm{k}=2$ in (5), the average wind speed based Rayleigh distribution function is given by:

$$
\bar{v}=c \Gamma\left(\frac{3}{2}\right)
$$

Rearrange (6) to find the scale factor based Rayleigh distribution function, yields:

$$
c=\frac{2 \bar{v}}{\sqrt{\pi}}
$$

By substituting (7) in (3), the probability for a specific wind speed based Rayleigh distribution function, $f_{R}(v)$, is given by:

$$
f_{R}(v)=\left(\frac{\pi}{2}\right)\left(\frac{v}{\bar{v}^{2}}\right) \exp -\left[(\pi / 4)\left(\frac{v}{\bar{v}}\right)^{2}\right]
$$

Fig. 2 shows Rayleigh distribution function at different average wind speeds. The maximum repetition wind speeds $\left(v_{R f \max }\right)$ is shown at the peak of each Rayleigh distribution function. It is clear that by increasing the average wind speed of the wind regime, the peak of the Rayleigh distribution function is decreased accordingly.

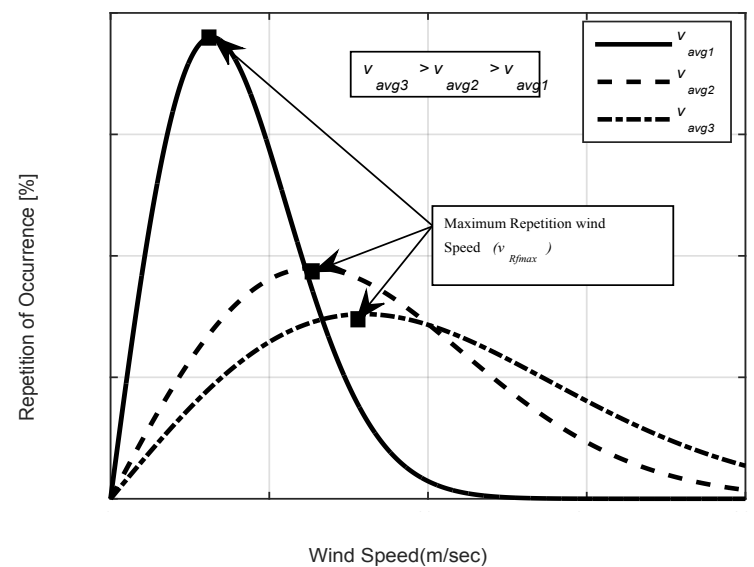

Figure 2. Rayleigh distribution function at different average wind speeds

\subsection{Wind Velocity at Different Height}

For winds near the ground surface, frictional effects play a significant role in the speed of the wind. Ground obstructions retard the movement of air close to the ground surface, causing a reduction in the wind speed. At some height above ground, called the gradient height $\left(Z_{G}\right)$, the movement of air is no longer affected by the ground obstructions. The unobstructed wind speed is called the gradient wind speed $\left(V_{z G}\right)$.

The power law, which is usually used to represent the variation of wind speed at different heights, is an empirical formula, in which the mean wind speed using this law can be evaluated as follows [6-7]:

$$
\left(\frac{V_{z}}{V_{z_{G}}}\right)=\left(\frac{Z}{Z_{G}}\right)^{\alpha}
$$

Where:

$V_{Z} \quad$ Wind speed at a specific height $\mathrm{Z}$.

$Z_{G} \quad$ Gradient height.

$\alpha \quad$ Exponent factor

$V_{Z G}$ Gradient wind speed.

Table 1. shows typical variations of wind speeds above different ground roughness [7]. In order to find the variation in the wind speed between two different positions with different terrain roughness and different height, (10) which is derived from (9) can be used:

$$
V_{z 1}=\left(\frac{\left(\frac{Z_{1}}{Z_{G 1}}\right)^{\alpha 1}}{\left(\frac{Z_{2}}{Z_{G 2}}\right)^{\alpha 2}}\right) V_{z 2}
$$

Where:

$V_{Z 1} \quad$ The wind speed at a height $Z_{1}$.

$V_{Z 2}$ The wind speed at a height $Z_{2}$.

$Z_{G 1}$ Gradient height for wind speed at position 1.

$Z_{G 2}$ Gradient height for wind speed at position 2 .

$\alpha_{1}$ Exponent factor for position 1.

$\alpha_{2} \quad$ Exponent factor for position 2.

$V_{Z G I}$ Gradient wind speed for position 1.

$V_{Z G 2}$ Gradient wind speed for position 2.

To consider the variation of the wind speed at a different height for the same position, (10) is simplified to the following:

$$
V_{z 11}=\left(\frac{Z_{1}}{Z_{2}}\right)^{\alpha} V_{z 12}
$$

Where:

$V_{Z 11} \quad$ Wind speed at a height $Z_{1}$ for position 1 .

$V_{Z 12} \quad$ Wind speed at a height $Z_{2}$ for position 1 . 
Table 1. Suggested values of $\mathrm{ZG}$ and $\alpha$ for various terrain conditions [6]

\begin{tabular}{|c|c|c|}
\hline Terrain description & $\begin{array}{c}\text { Gradient height } \mathrm{Z}_{\mathrm{G}} \\
(\mathrm{m})\end{array}$ & $\begin{array}{c}\text { Power-law } \\
\text { exponent }(\alpha)\end{array}$ \\
\hline Rough sea & 250 & 0.12 \\
\hline Open grassland & 300 & 0.15 \\
\hline suburban areas & 370 & 0.22 \\
\hline City centers & 460 & 0.33 \\
\hline
\end{tabular}

\section{Wind Energy Based on Rayleigh Approach}

The energy density for a specific wind regime is defined as the total energy contributed by all possible wind speeds in that regime. For the case of the Rayleigh approach, it can be expressed as follows:

$$
E_{D R}=\int_{0}^{\infty} P_{w}(v) f_{R}(v) d v
$$

Where $E_{D R}$ is the wind energy density based on the Rayleigh approach. By Substituting (1) and (8) in (12) and simplifying the equation, yields:

$$
\begin{aligned}
& E_{D R}=\left(\frac{\pi \rho}{4 \bar{v}^{2}}\right) \int_{0}^{\infty} v^{4} \exp -\left[(\pi / 4)\left(\frac{v}{\bar{v}}\right)^{2}\right] d v \\
& =A \rho \int_{0}^{\infty} v^{4} \exp -\left[(\pi / 4)\left(\frac{v}{\bar{v}}\right)^{2}\right]
\end{aligned}
$$

To simplify (13), the internal integration has to be solved. For this reason, assume $\mathrm{y}=A v^{2}$. Substitute (y) in (13) and simplify the equation, yields:

$$
E_{D R}=\frac{\rho}{2 A^{3 / 2}} \Gamma\left(\frac{5}{2}\right)
$$

Equation 14 can be reduced using gamma identities, $\Gamma\left(\frac{5}{2}\right)=\frac{3}{4} \sqrt{\pi}$. The simplified equation is:

$$
E_{D R}=\frac{3}{\pi} \rho \bar{v}^{3}
$$

Therefore, the energy available in a wind regime expressed by a Rayleigh distribution function over a time period of (T hours) is given by $E_{T R}$.

Where:

$$
E_{T R}=\frac{3}{\pi} T \rho \bar{v}^{3}
$$

For any wind regime represented by a specific probability density function, two wind speeds are required to be known. These wind speeds are $v_{F \max }$ and $v_{E \max }$. Where $v_{\text {Fmax }}$ is the most frequent wind speed in the regime and $v_{E \max }$ is the wind speed contributing the maximum energy to that regime.

For a wind regime expressed by a Rayleigh distribution function, these wind speeds are $v_{\text {RFmax }}$ and $v_{\text {REmax }}$, where the subscript (R) is related to the Rayleigh distribution function. To find $v_{R F m a x}$, the first derivative of the Rayleigh distribution function of the wind regime $f_{R}(v)$ has to be evaluated and equated to zero $\left(\left(d f_{R}(v) / d v\right)=0\right)$. By solving this equation, the maximum repetition wind speed using Rayleigh approach $\left(v_{\text {RFmax }}\right)$ can be evaluated as follows:

$$
v_{R F \max }=\sqrt{2 / \pi} \bar{v}
$$

In order to find the second term $v_{R E \max }$, the first derivative of $P_{R}(v) f_{R}(v)$ has to be evaluated and equated to zero, $d\left(P_{R}(v) f_{R}(v)\right) / d v=0$. Solving the previous equation, $\left(v_{\text {REmax }}\right)$ can be represented as follows:

$$
v_{R E \max }=\sqrt{2 / A}=\sqrt{8 / \pi} \bar{v}
$$

\section{Methodology of Estimating Wind Energy}

Consider a case study of assessing and estimating the wind energy in a specific wind site, say in Jordan. This includes the determination of the main parameters of any wind regime $v_{\text {Fmax }}, v_{\text {Emax }}$ and $E_{T}$.

The monthly average wind speed for a selected site can be obtained from the website in which the height of the provided wind data is also given.

The concept of this methodology is based on estimating the required parameters by extracting the wind speed data on an hourly basis for one year. For this reason, a random Rayleigh function based Matlab software (raylrnd) was used to generate a series of wind speed data for one year on an hourly basis. Fig. 3 shows the generated wind speed data using (raylrnd) Matlab function for Tafila wind site.

Based on the generated wind database, the most frequent wind speed $\left(v_{F \max }\right)$ is obtained using the MODE function in an Excel environment which returns the most frequently occurring number in a numeric data set [25]. In order to estimate the second parameter $\left(v_{E \max }\right)$ using the generated wind database, the power for each wind speed from $(3-25 \mathrm{~m} / \mathrm{s})$, which is the regular wind speed range of the operating region for any wind turbine, is evaluated using (1). The effect of the wind speed repetition in the wind regime is included using the COUNTIF Excel function which returns the repetition of a specific number in a series of data in the Excel environment. Therefore, the energy contributed by each wind speed can be evaluated. Then, $v_{E \max }$ for a specific wind regime can be estimated by selecting the wind speed contributing the maximum energy. Finally, the power of all wind speeds has to be added in order to estimate the third parameter $\left(E_{T}\right)$ using this methodology. The procedure of this methodology can be done routinely to assess the wind energy for any wind site. 
In Jordan, there are several potential sites of wind energy that can be used for developing future projects of WECS. The selected sites in this study are Zabda, Tafila, Alalia, Royal Scientific Society (RSS) and Al-reesha.

The circular points in Fig. 4 shows the location of these sites in the Jordan map. It is clear that they are spread in several places in Jordan. The monthly average wind speed for these sites is provided by several wind online systems such as the one in [26]. Using the methodology described in this section, the assessment of the wind sites can be done by estimating the main parameters of these sites $v_{F \max }, v_{\text {Emax }}$. Table 2 shows the online monthly average wind speed for these sites with their corresponding height. Fig. 5 shows the estimated total energy using the developed methodology with the online wind data. The estimated wind parameters for these sites are shown in Table 3. In order to validate this methodology, a comparison study with real measurements wind data have to be done. This will be described in the following section.

Table 2. Online wind speed data for the selected wind sites $[25,26]$

\begin{tabular}{|c|c|c|c|c|c|}
\hline \multirow{2}{*}{ Month Location } & \multicolumn{5}{|c|}{ Wind Speed (m/s) } \\
\hline & Tafila & Zabda & Royal Scientific Society & Al-Alia & Al-Reesha \\
\hline Jan. & 10.1 & 7.6 & 5.5 & 7.2 & 8.7 \\
\hline Feb. & 11.1 & 8.3 & 6.3 & 6.5 & 8.2 \\
\hline March & 10.5 & 7 & 5.5 & 6.1 & 7.3 \\
\hline April & 9.1 & 7.4 & 5.9 & 5.5 & 6.1 \\
\hline May & 7.8 & 7.6 & 5.2 & 5.2 & 5.1 \\
\hline June & 8 & 7.3 & 5.9 & 5.1 & 5.1 \\
\hline July & 7.8 & 7.6 & 6.8 & 5.4 & 5.4 \\
\hline August & 7.6 & 6.8 & 5.4 & 5.9 & 5.5 \\
\hline Sept. & 6 & 6 & 5.7 & 7.5 & 5.9 \\
\hline Oct. & 5.9 & 5.3 & 4.7 & 8.7 & 6.3 \\
\hline Nov. & 8.9 & 6.2 & 4.8 & 8.9 & 7.8 \\
\hline Dec. & 9 & 7.1 & 5.7 & 49 & 7.5 \\
\hline Height $(\mathrm{m})$ & 45 & 50 & 50 & 50 \\
\hline
\end{tabular}

Table 3. Online wind speed data for the selected wind sites $[25,26]$

\begin{tabular}{|c|c|c|}
\hline & $v_{\text {RFmax }}(\mathrm{m} / \mathrm{s})$ & $v_{\text {REmax }}(\mathrm{m} / \mathrm{s})$ \\
\hline Tafilah & 7 & 14 \\
\hline Zabda & 6 & 12 \\
\hline Royal Scientific Society & 4 & 9 \\
\hline Al-Alia & 5 & 10 \\
\hline
\end{tabular}

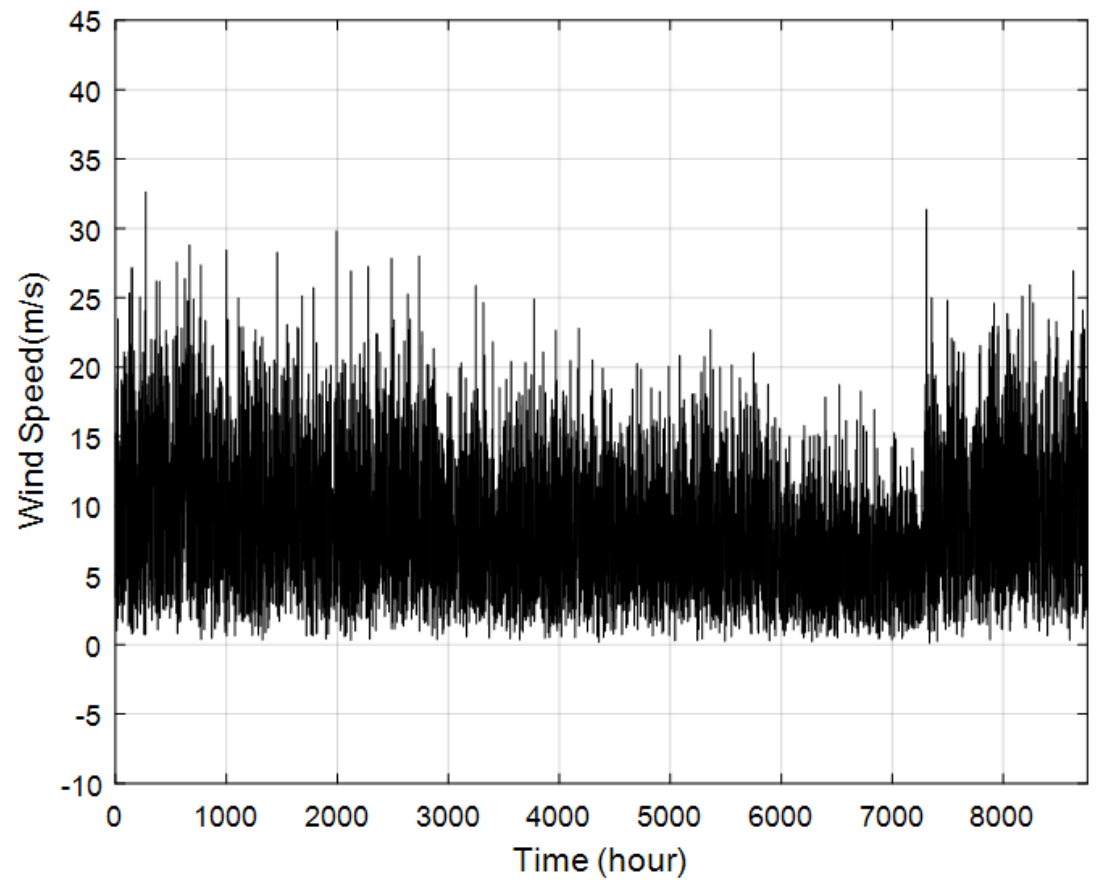

Figure 3. Generated wind speed data using (raylrnd) Matlab function for Tafila wind site 


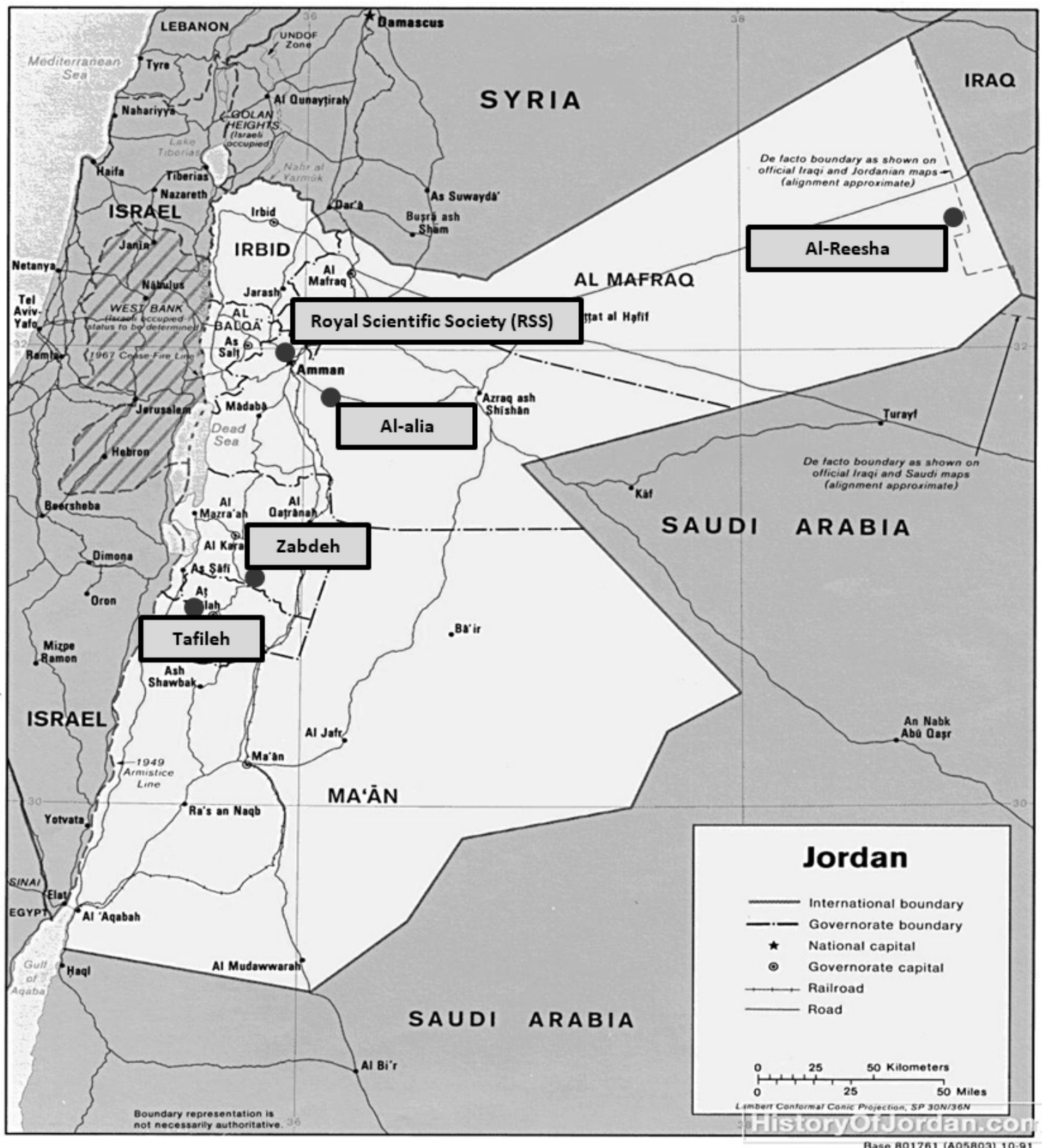

Figure 4. Location of the selected wind sites in Jordan map [22]

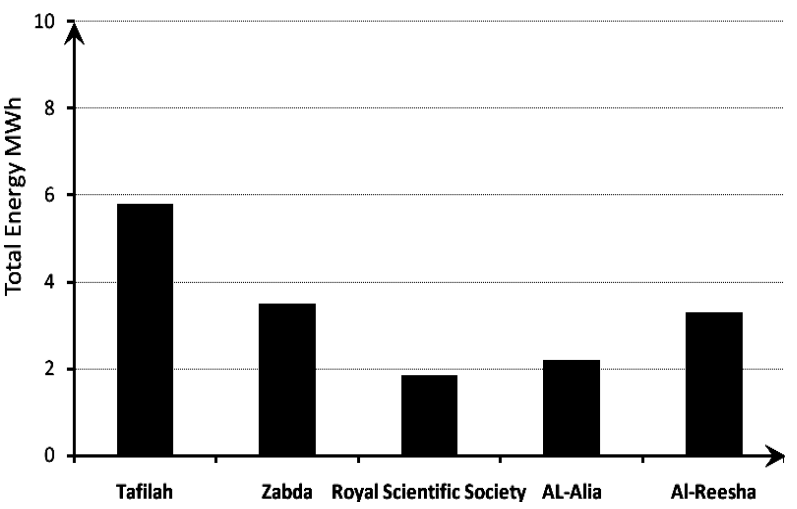

Figure 5. Total energy estimated using the developed methodology and the online wind data

\section{Energy Research Centre and Measured Wind Data}

The Energy Research Centre of the Royal Scientific Society, which is responsible for research and establish standards related to renewable energy studies, measured the wind speed in several promising locations in Jordan at different heights [18]. The measurement of the wind speed is done every second using several types of three-cup anemometers which save the wind data in their loggers averaged in 10 minutes basis.

As previously mentioned, the selected sites in this study are: Zabda, Tafila, Alalia, Royal Scientific Society (RSS) and Al-reesha wind sites. The coordination for these sites is brought originally from the Energy Research Centre in 
WGS84 format which stands for World Geodetic System. It was developed by the Defense Mapping Agency in 1984 and it is an updated version of the WGS72 system. WGS 84 provides a standard coordinate system for the Earth, which is based on the Universal Transverse (UTM) zone that used a 2D cartesian coordinates to determine locations on the Earth [18]. Table 4 shows the coordination for these sites in WGS84 format and in Degrees, Minutes, Seconds (DMS) format which is more common. The latest can be directly inserted to Google Earth to show the location of interest having longitude and latitude. There are many websites provide online converters between these two well-known formats such as the ones in $[20,21]$.

Table 5 shows the measured wind speed provided by the Energy Research Centre for the selected sites at different heights from the ground averaged in monthly basis. It is obvious that the monthly average wind speed for these sites is greater than $5 \mathrm{~m} / \mathrm{s}$ which is considered as a good source of wind energy.

The measured wind speed by the Energy Research Centre was used for wind site assessment by evaluating the required parameters $E_{T R}, v_{R F \max }$ and $v_{R E \max }$ using (23) and (25) respectively. Table 6 shows these parameters for all selected sites. The total energy evaluated using the measured wind speed based on Rayleigh approach is shown in Fig. 6. The percentage error between the estimated and the measured energy is shown in Fig. 7. The error was evaluated based on the following definition:

$$
\text { Error }=\left|\frac{E_{T_{-} \text {estimated }}-E_{T_{-} \text {measured }}}{E_{T_{-} \text {measured }}}\right| \times 100 \%
$$

Where:

$E_{T_{\text {_estimated }}}$ Energy estimated using the developed methodology.

$E_{T_{-} \text {measured }}$ Energy evaluated using the measured wind data.

Table 4. Coordinates conversion (WGS84 to DMS format)

\begin{tabular}{|c|c|c|}
\hline & Coordinates (WGS84 Format) & Coordinates (DMS Format) \\
\hline Tafilah & E 757578, N 3406276 & $30^{\circ} 45^{\prime} 41.8^{\prime \prime} \mathrm{N}, 35^{\circ} 41^{\prime} 27.5^{\prime \prime} \mathrm{E}$ \\
\hline Zabda & E 762023, N 3415405 & $30^{\circ} 50^{\prime} 34.4^{\prime \prime} \mathrm{N}, 35^{\circ} 44^{\prime} 22.9^{\prime \prime} \mathrm{E}$ \\
\hline Royal Scientific Society & E 771950, N 3547049 & $32^{\circ} 1^{\prime} 37.02^{\prime \prime} \mathrm{N}, 35^{\circ} 52^{\prime} 45.98^{\prime \prime} \mathrm{E}$ \\
\hline Al-Alia & E 791995.7, N3529316.5 & $31^{\circ} 51^{\prime} 44.0^{\prime \prime} \mathrm{N}, 36^{\circ} 05^{\prime} 09.9^{\prime \prime} \mathrm{E}$ \\
\hline Al-Reesha & E 501090, N 3603669 & $32^{\circ} 34^{\prime} 13.66^{\prime \prime} \mathrm{N}, 39^{\circ} 00^{\prime} 41.8^{\prime \prime} \mathrm{E}$ \\
\hline
\end{tabular}

Table 5. Measured wind speed for the selected sites at different height by Energy Research Centre

\begin{tabular}{|c|c|c|c|c|c|}
\hline \multirow{2}{*}{ Location } & \multicolumn{5}{|c|}{ Wind Speed (m/s) } \\
\cline { 2 - 6 } & Tafila & Zabda & $\begin{array}{c}\text { Royal Scientific } \\
\text { Society }\end{array}$ & Al-Alia & Al-Reesha \\
\hline Jan. & 10.69 & 8.05 & 5.28 & 6.82 & 8.38 \\
\hline Feb. & 9.23 & 8.95 & 6.15 & 7.10 & 7.76 \\
\hline March & 9.69 & 6.62 & 5.93 & 6.19 & 7.21 \\
\hline April & 9.08 & 7.61 & 5.45 & 6.41 & 6.2 \\
\hline May & 7.82 & 7.50 & 5.04 & 6.45 & 7.37 \\
\hline June & 8.16 & 7.35 & 5.61 & 6.65 & 6.73 \\
\hline July & 7.79 & 7.96 & 6.45 & 6.23 & 5.92 \\
\hline August & 7.60 & 7.12 & 5.59 & 6.32 & 6.27 \\
\hline Sept. & 6.28 & 6.26 & 5.36 & 5.31 & 6.65 \\
\hline Oct. & 5.86 & 5.98 & 4.37 & 5.04 & 5.48 \\
\hline Nov. & 8.86 & 6.32 & 4.76 & 6.81 & 7.21 \\
\hline Dec. & 9.38 & 7.11 & 5.53 & 49 & 5 \\
\hline Height $(m)$ & 45 & 50 & 45 & & 5.7 \\
\hline
\end{tabular}

Table 6. Wind parameters evaluated based on measured wind speed

\begin{tabular}{|c|c|c|}
\hline & $v_{R F \max }(\mathrm{m} / \mathrm{s})$ & $v_{\text {REmax }}(\mathrm{m} / \mathrm{s})$ \\
\hline Tafilah & 6.7 & 13.4 \\
\hline Zabda & 5.7 & 11.5 \\
\hline Royal Scientific Society & 4.4 & 8.8 \\
\hline Al-Alia & 4.9 & 9.9 \\
\hline Al-Reesha & 5.6 & 11.2 \\
\hline
\end{tabular}


It can be shown from Fig. 6 that the maximum error in the energy estimation is less than $10 \%$, which means that this methodology is sufficiently accurate to be used at least in the initial stages of the Wind Energy Conversion System (WECS) development and wind farms installation.

\section{Generated Data Base at Standard Height}

Since the wind speed varies with height, it is preferred to compare the wind energy between different sites at a uniform height. Therefore, the generated wind database for the selected wind sites are converted to the standard height $(10 \mathrm{~m})$. If the wind site is potential at $10 \mathrm{~m}$ height, then it is also potential at the hub height of the wind turbine which is greater than $10 \mathrm{~m}$. This is correlated with the fact that the wind speed is increasing with height [22-24, 27]. Equation 10 is used in the conversion process of the generated database. At $10 \mathrm{~m}$ height, (10) can be rewritten as:

$$
\left(\frac{V_{10}}{V_{z_{G}}}\right)=\left(\frac{10}{Z_{G}}\right)^{\alpha}
$$

Where $V_{10}$ is the wind speed at $10 \mathrm{~m}$ height. Divide (20) on (10) and simplify the equation, yields:

$$
V_{10}=\left(\frac{10}{Z}\right)^{\alpha} V_{z}
$$

Since the online wind speed for all sites is provided in free space areas [26], an exponent factor of 0.15 is used in (21) to extrapolate the wind speed at $10 \mathrm{~m}$. This value is the second category in Table 1.

Fig. 8 shows that the wind energy of Al-Reesha site is greater than that of Zabda site, which is different than the result obtained in Fig. 6. The reason is that the original wind speed given by the Energy Research Centre was measured at different height, see Table 5 for the height of the measured wind speed for all sites. It is clear that the height of the measured wind speed of Zabda site is greater than the one of Al-Ressha site. Knowing that comparing the wind speed at different height is ineffectual for comparing the potential of the wind energy at different sites. It is also clear from Fig. 8 that $E_{T}$ for Tafilah site is the highest among the other sites.

The other factors $v_{\text {RFmax }}$ and $v_{\text {REmax }}$ were evaluated using the generated database at the standard height. Table 7 shows comparisons between these factors for all sites at the standard height. The wind speed contributing maximum energy $\left(v_{\text {REmax }}\right)$ in Tafilah site is $6 \mathrm{~m} / \mathrm{s}$ which is considered as good wind speed at this height $(10 \mathrm{~m})$.

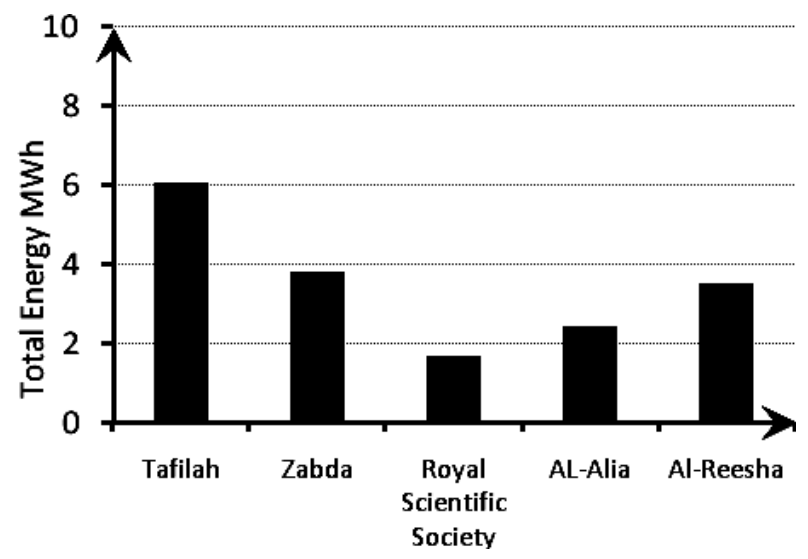

Figure 6. Total energy evaluated based Rayleigh approach

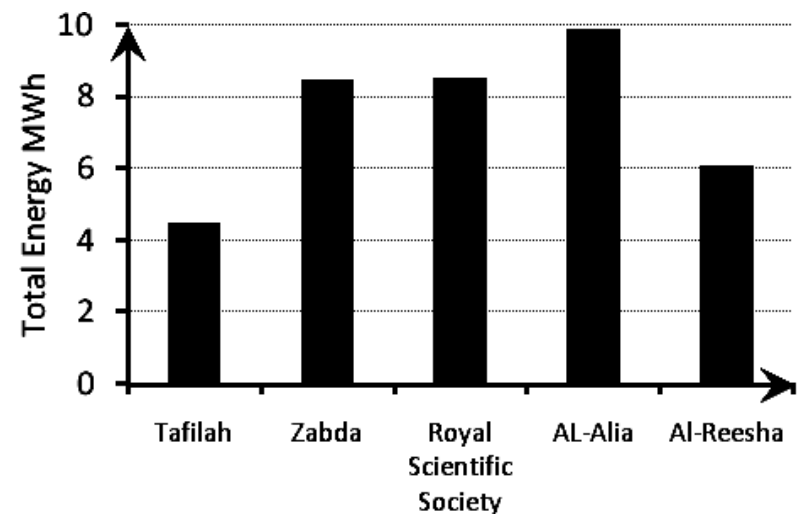

Figure 7. Error calculations between measured and estimated wind energy

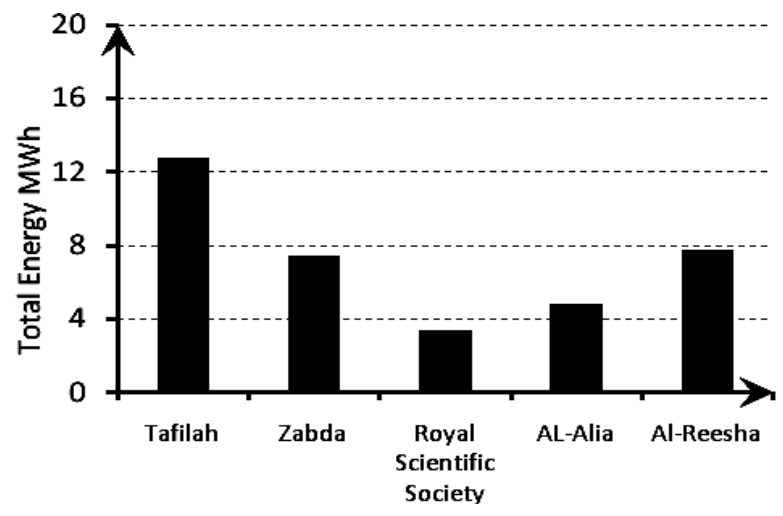

Figure 8. Estimated energy of the selected wind sites at $10 \mathrm{~m}$ height

Table 7. Estimated wind parameters at $10 \mathrm{~m}$ Height

\begin{tabular}{|c|c|c|}
\hline & $v_{\text {RFmax }}(\mathrm{m} / \mathrm{s})$ & $v_{\text {REmax }}(\mathrm{m} / \mathrm{s})$ \\
\hline Tafilah & 5 & 6 \\
\hline Zabda & 4 & 5 \\
\hline Royal Scientific Society & 3 & 3 \\
\hline Al-Alia & 4 & 4 \\
\hline Al-Reesha & 4 & 5 \\
\hline
\end{tabular}




\section{Conclusions}

This paper presented a technical assessment of wind power potential for five promising wind sites in Jordan. The selected sites in this study were Tafila, Zabda, Royal Scientific Society, Al-Alia and Al-Reesha wind sites. The wind assessment of these sites was based on developing a new methodology of estimating the wind energy. This methodology can be utilized routinely to assess the wind energy for any wind site. It depends on Microsoft Excel environment and website data, provided by the wind energy atlas, to estimate the main parameters of the selected wind sites. The validation process was done using measured wind speed data provided by the National Energy Research Centre. The error calculations show that the estimated total energy using the developed methodology is accurate enough to be used, at least, in the initial stages of developing any wind farms. To achieve a true comparison between the wind energy of the selected sites, the wind energy was estimated at uniform height, selected to be the standard height $(10 \mathrm{~m})$. From another point of view, this methodology assists the Jordanian government strategy in finding easily the potential wind sites in the country, so that a decision can be made whether a wind farm can be built or not without any need to install anemometers.

\section{Acknowledgements}

The authors acknowledge Yarmouk University, and the National Research Energy Centre for their support in this study.

\section{REFERENCES}

[1] T. Simões and A. Estanqueiro, "A new methodology for urban wind resource assessment", Elsevier Journal of Renewable Energy, vol. 89, pp. 598-605, April 2016.

[2] An-ShikYang, Ying-MingSu, Chih-Yung Wen, Yu-Hsuan Juan, Wei-Siang Wang, Chiang-Ho Cheng, "Estimation of wind power generation in dense urban area", Elsevier Journal of Applied Energy, vol. 171, pp. 213-230, June 2016.

[3] An-ShikYang, Ying-MingSu, Chih-Yung Wen, Yu-Hsuan Juan, Wei-Siang Wang, Chiang-Ho Cheng, "Urban wind conditions and small wind turbines in the built environment: A review", Elsevier Journal of Renewable Energy, vol. 131, pp. 268-283, February 2019.

[4] Rakesh Kumar, Kaamran Raahemifar, Alan S. Fung, "A critical review of vertical axis wind turbines for urban applications", Elsevier Journal of Renewable and Sustainable Energy Reviews, vol. 89, pp. 281-291, June 2018.
[5] Xiao-Yu Tang, Shumian Zhao, Bo Fan, Joachim Peinke, Bernhard Stoevesandt, "Micro-scale wind resource assessment in complex terrain based on CFD coupled measurement from multiple masts", Elsevier Journal of Applied Energy, vol. 238, pp. 806-815, March 2019.

[6] A. Al-Quraan, T. Stathopoulos, P. Pillay, "Comparison of Wind Tunnel and on Site Measurements for Urban Wind Energy Estimation of Potential Yields", Elsevier Journal of Wind Engineering and Industrial Aerodynamics, vol. 158, pp. 1-10, November 2016.

[7] A. Al-Quraan, P. Pillay, T. Stathopoulos, "Use of a Wind Tunnel for Urban Wind Power Estimation", In Proceedings of IEEE Power \& Energy Society General Meeting, Washington, USA, 27-31 July 2014.

[8] Ted Stathopoulos, Hatem Alrawashdeh, Ayman Al-Quraan, Bert Blocken, Aierken Dilimulati, Marius Paraschivoiu, Pragasen Pillay, "Urban Wind Energy: Some Views on Potential and Challenges", Elsevier Journal of Wind Engineering and Industrial Aerodynamics, vol. 179, pp. 146-157, August 2018.

[9] Sidi Mohammed Boudia, Abdelhalim Benmansour, Mohammed Abdellatif Tabet Hellal, "Wind resource assessment in Algeria", Elsevier Journal of Sustainable Cities and Society, vol. 22, pp. 171-183, April 2016.

[10] Lizica-Simona Paraschiv, Spiru Paraschiv, Ion V. Ion, " Investigation of wind power density distribution using Rayleigh probability density function ", Elsevier Journal of Energy Procedia, vol. 157, pp. 1546-1552, January 2019.

[11] Muhammad Shoaib, Imran Siddiqui, Shafiqur Rehman, Shamim Khan, Luai M. Alhems, "Assessment of wind energy potential using wind energy conversion system", Elsevier Journal of Cleaner Production, vol. 216, pp. 346-360, April 2019.

[12] Kalam Azad, Mohammad. Rasul, Pobitra Halder, J. Sutariya, "Assessment of Wind Energy Prospect by Weibull Distribution for Prospective Wind Sites in Australia", Elsevier Journal of Energy Procedia, vol. 160, pp. 348-355, February 2019.

[13] Hicham Bidaoui, Ikram El Abbassi, Abdelmajid El Bouardi, Abdelmoumen Darcherif, "Wind Speed Data Analysis Using Weibull and Rayleigh Distribution Functions, Case Study: Five Cities Northern Morocco", Elsevier Journal of Procedia Manufacturing, vol. 32, pp. 786-793, 2019.

[14] http://memr.gov.jo/DetailsPage/MOE_EN/NewsEN.aspx?P ID=202 (Accessed by: 22/5/2019).

[15] https://www.thewindpower.net/windfarm_en_24721 maan. php (Accessed by: 22/5/2019).

[16] Ayman Al-Quraan, Hatem Alrawashdeh, “Correlated Capacity Factor Strategy for Yield Maximization of Wind Turbine Energy", In Proceedings of the IEEE 5th International Conference on Renewable Energy Generation and Applications (ICREGA), Al-Ain, UAE, 26-28 February 2018.

[17] S. Mathew, K. P. Pandey and A. Kumar, "Analysis of Wind Regimes for Energy Estimation" Elsevier Journal of Renewable Energy, vol. 25, issue 3, pp. 381-399, March 2002. 
[18] "National Energy Research Center", [Available online]: http://www.nerc.gov.jo/Pages/viewpage.aspx?pageID=156 (Accessed by: 22/5/2019).

[19] Decker, B. Louis, "World geodetic system 1984. Defense Mapping Agency Aerospace Center St Louis Afs Mo, 1986.

[20] "Convert between Latitude/Longitude \&UTM coordinates / MGRS grid references", [Available online]: https://www.movable-type.co.uk/scripts/latlong-utm-mgrs.h tml (Accessed by: 28/8/2018).

[21] Engineering ToolBox, "UTM to Latitude and Longitude Converter", [Available online]: https://www.engineeringtoo lbox.com/utm-latitude-longitude-d_1370.html (Accessed by: $28 / 8 / 2018)$

[22] http://www.historyofjordan.com/jordan2/jh/collection1.php ?id=104\&page $=5495$ (Accessed by: 6/10/2018).
[23] A. Al-Quraan, T. Stathopoulos, P. Pillay, "Estimation of Urban Wind Energy- Equiterre Building Case in Montreal", In Proceedings of the International Civil Engineering for Sustainability and Resilience Conference (CESARE'14), Irbid, Jordan, 24-27 April 2014.

[24] https://www.excelfunctions.net/excel-mode-function.html (Accessed by: 22/5/2019).

[25] https://jordan.gov.jo/wps/portal/Home/GovernmentEntities/ Agencies/Agency/Royal\%20Scientific\%20Society?nameEn tity=Royal\%20Scientific\%20Society\&entity Type=otherEnt ity (Accessed by: 19/12/2018).

[26] https://globalwindatlas.info (Accessed by: 22/5/2019).

[27] H. M. Al-Masri, A. Al-Quraan, A. AbuElrub, M. Ehsani, "Optimal Coordination of Wind Power and Pumped Hydro Energy Storage". MDPI Journal of Energies, vol. 12, no. 22, 4387, pp. 1-15, 2019 